\title{
HEALTH CARE PROFESSIONALS' ROLE IN PREVENTING CHILD HOMICIDES IN THE CONTEXT OF DOMESTIC VIOLENCE
}

Faculty of Education and Centre for Research and Education on Violence Against Women and Children, Western University London ON Canada

Peter Jaffe

Faculty of Education

Western University

1137 Western Road

London ON Canada N6G 1G7

pjaffe@uwo.ca

Tel.: + 519-661-2018

Fax.: + 519-850-2464

Received: November 20, 2012

Accepted: January 9, 2013

Copyright (C) 2013 by

University Clinical Center Tuzla.

E-mail for permission to publish:

paediatricstoday@ukctuzla.ba
Peter G. JAFFE, Marcie CAMPBELL, Laura P. OLSZOWY

This review article highlights the risks that children may face in the context of domestic violence (DV). Although there are significant risks for psychological harm for children exposed to $\mathrm{DV}$, in extreme cases, children may be exposed to a domestic homicide or become homicide victims themselves. Often these tragedies appear predictable and preventable with the presence of several risk factors. Risk assessment tools currently being used to identify the level of risk to an adult victim of DV also indicate a potential risk to a child. Health care professionals need to be aware of the risk for lethality with children exposed to DV and to raise these issues with patients in consideration of the risk to children. Prevention of these tragedies requires enhanced training on domestic violence and the risk for lethality with victims and children. Standardized protocols for interventions and risk management that include safety plans for children are needed. Conclusion - Reviews of domestic homicides suggest that children may be at significant risk of harm and health care professionals need to recognize that risks to adult partners in these circumstances also pose risks to children.

Key words: Domestic violence - Child abuse - Homicide

\section{Introduction}

Domestic violence (DV) is a problem across the world. For example, it is estimated that 1.5 million women experience domestic violence (DV) each year in the United States (1). In Canada, there were over 102,500 victims of DV in 2010 with women being almost four times more likely to be victims than men (2). Research in Bosnia and Herzegovina has demonstrated that the impact of this violence may be 
associated with long-term mental health problems in women which can be accentuated by other factors such as a childhood history of violence or living in a war-torn country (3).

Domestic violence can also have an impact on children. Children exposed to DV may witness and/or hear the violence; they may see direct consequences of the violence such as emotional distress, bruises or wounds. Children may be directly involved with the violence while attempting to intervene or getting caught in the crossfire between parents (4). Between 2001 and 2005, 35\% of U.S. households experiencing DV had children residing in the home (5). In 2009, 52\% of DV victims in Canada indicated that their children had witnessed a violent incident within the past five years and $5 \%$ of DV victims indicated that their children were harmed during a violent incident (2).

There has been a dramatic growth in our understanding of the harm posed to children exposed to DV. In fact, research on the effects of childhood exposure to DV has increased dramatically since the early 1990s (4). Children exposed to DV may have more behavioural problems, social problems, emotional issues, and symptoms of PTSD compared to children not exposed to DV $(6,7)$. Furthermore, some children may adopt distorted attitudes and beliefs regarding relationship violence and their own use of abusive behaviours $(8$, 4). For example, some children exposed to DV may be at increased risk to use violence in their own romantic and peer relationships as teens and young adults $(9,10)$.

In the early 1980s, DV was seen as a crime in most states and Canadian provinces/territories, yet children exposed to DV were seen only as "secondary victims." However, by the early 1990s, six Canadian provinces and one territory (Alberta, Saskatchewan, Prince Edward Island, Newfoundland, New Brunswick, Nova Scotia, and Northwest Territories) created legislation that stated child exposure to DV should be considered a form of child maltreatment $(4,11)$. In the U.S., Montana and Puerto Rico included exposure to DV in their definition of child maltreatment, specifically considering exposure as a form of child abuse and neglect (11). These changes in legislation (change to laws) have dramatically increased the involvement of child protection services (CPS) with families experiencing DV, often with CPS intervening by providing referrals, counselling, risk assessment and/or safety plans to help minimize the risk of further exposure $(12,13)$.

Parallel to legislative changes has been the demands of professionals in the health care, social service and education sectors to be more aware of the impact of DV on children. This demand has been reflected in enhanced training and protocols for screening and intervention. This trend has been apparent within the health care sector as research has stressed the importance of various specializations within medicine (e.g., pediatrics, family practice, obstetrics and emergency services) to assess patients for histories of DV (14). Estimates from primary care health professionals suggest that close to one in five patients seeking assistance are dealing with DV victimization (15).For well over a decade, the American Academy of Pediatrics has highlighted the critical role that pediatricians can play in assessing the impact of DV on adult victims and their children as well as ensuring that referrals and collaboration with other service providers takes place (16). In spite of the progress in the field, many professionals in health care and other human services may underestimate the potential risk to children in extreme cases of DV, such as being exposed to domestic homicide or being a victim themselves. Reviews from medical examiners and coroners' committees suggest that children may be at risk of homicide in extreme circumstances. Retrospective accounts from many of these tragedies suggest that warning signs are often overlooked or misunderstood by helping professionals (17). 


\section{Domestic homicide and adult victimization}

Extreme intimate partner violence can result in homicide. In Canada, there were 65 spousal homicides (a homicide committed by a married, separated, divorced or common-law partner) and 24 dating homicides (a homicide committed by a current or previous boyfriend or girlfriend) in 2010. The rate of female victims was almost three times higher than male victims among spousal homicides and almost two times higher among dating homicides (2). In 2007, it was estimated that a total of 2,340 intimate partner homicides occurred in the U.S. with the rate of female victims being over two times the rate of male victims (18).

The majority of domestic homicides appear predictable and preventable due to the high number of risk factors present within the family. These risk factors are most often known to family, co-workers and frontline professionals prior to the tragedy. The Ontario Domestic Violence Death Review Committee (Ontario DVDRC) indicated that there were seven or more risk factors identified in $76 \%$ of the domestic homicide cases reviewed between 2003 and 2011 (19). Research has shown that common risk factors for domestic homicide include a history of domestic violence, an actual or pending separation, obsessive-possessiveness on the part of the perpetrator, prior police involvement, the perpetrator having a criminal history, substance abuse issues, child custody and access disputes, perpetrator mental illness, step children in the home, prior threats to kill and the victim's intuitive sense of fear $(20,21,19)$.

\section{Domestic homicide and child victimization}

In some domestic homicide cases, there may be "collateral" victims such as allies, new partners, bystanders, and children (22). It is estimated that approximately 3,300 children in the United States are impacted by domestic homicide every year (23). There are many ways that children can be affected by domestic homicide: they may be exposed to the homicide (e.g., witnessing the homicide itself or the aftermath of the tragedy); they may become an indirect victim while attempting to protect their parent from the violence; they may be direct targets of the perpetrator as a form of revenge or as a victim of a familicide (the killing of the entire family); or they may be left without parents as a result of a homicide-suicide or one $\mathrm{pa}$ rent being killed and the other imprisoned (24). One study found that in 121 cases of an actual or attempted homicide of a woman by her intimate partner, children witnessed the violence in $35 \%$ of the actual homicide cases and $62 \%$ of the attempted homicide cases. Furthermore, children discovered their mother's body in $37 \%$ of the actual homicide cases and $28 \%$ of the attempted homicide cases (23). Another study looked at findings on children impacted by domestic homicide from 17 domestic violence death review committees across the United States and Canada (17). Overall 1,006 incidents of domestic homicide were documented with a total of 1,397 deaths, 95 being child deaths. In 920 incidents of domestic homicide, 273 children were present during the homicide and 199 children witnessed the incident.

Children exposed to domestic homicide experience profound trauma that can lead to several mental, physical, behavioral and academic adjustment problems (25). Children may experience depression, anxiety, grief, post-traumatic stress, and suicidal ideation. Furthermore, they may experience several somatic issues, such as stomachaches or headaches, and significant weight and appetite changes. Children may also engage in several maladaptive behaviors, such as general rebellion, illegal activity, conflict with peers, and general destructive and impulsive behaviors 
(25). Some children may have fantasies about seeking revenge or being reunited with the deceased parent. These fantasies are usually accompanied with feelings of guilt, powerlessness, self-blame, anger and depression. It can often be difficult for these children to develop secure attachments and form new positive relationships (26). Often children exposed to domestic homicide do not receive the support required to help them cope with their experienced trauma. This may be due in part to symptoms of trauma not being recognized by caregivers who are attempting to re-establish routine in the children's lives or it may be due to the significant delays and wait times in receiving trauma counselling $(27,28)$.

\section{Risk factors associated with child victims of domestic homicide}

There has been some research that has indicated particular risk factors associated with child victims of domestic homicide $(29,30$, 31). Factors such as an actual or pending separation between the couple, perpetrator unemployment, psychological instability, and substance abuse were all identified in domestic homicide cases that involved the death of a child (30). Websdale identified a history of child abuse, domestic violence within the family, and prior family involvement with agencies as antecedents to domestic homicide involving a child victim (31). In fact, many child domestic homicides are preceded by child maltreatment, with one study finding that over $30 \%$ of domestic homicides involving child deaths had a history of child physical abuse or neglect (29).

Many research studies examining factors associated with child domestic homicide do not use a comparison sample and therefore they can only provide descriptive information about child homicides rather than potential factors that place a child at a greater risk for lethality. In recent research that attempted to identify unique factors that place children at risk of homicide in a domestic violence context, domestic homicide cases that involved children were compared to domestic homicide cases that did not involve children (32). The only significant difference found between these cases was that domestic homicide cases involving children had more community agency involvement than cases that did not involve children. The authors provided a few explanations for this difference such as: adding children to the family system increases the number of people within that system and naturally increases the overall agency involvement; often communities have an increased number of services to assist children and therefore families with children may be involved with more community agencies because more are available to them; or parents in the process of separating are often involved with the family court system to work out custody and access arrangements compared to separating couples without children (32). More extensive research needs to be conducted, using comparison samples, to identify risk factors that are specifically associated with children at risk for lethality. Nonetheless the current research should guide practitioners to be aware that when adult victims are in danger of lethal violence, their children may also be at risk.

\section{Assessing risk for child domestic homicide}

There are a number of tools that have been developed to assess the risk of reoffending or the risk of lethality for victims of DV; yet these specific tools have not been designed to specifically assess the risk of lethality for children exposed to DV (33). Some risk assessment tools may ask questions related to children in the family, such as whether the perpetrator has ever threatened to harm the 
children; however these types of factors are related to victim risk and not child risk per se although on they have obvious face validity as a risk to children. Often child protection services (CPS) use risk assessment tools that measure overall maltreatment recurrence, and most times, in the absence of maltreatment in a family experiencing DV, exposure to DV is not seen as a specific risk factor for child lethality (34).

The Australian government recently issued a report titled, "Screening and Assessment in the family relationship centres and the family relationship advice line" (35). This report provides a guide for frontline workers on how to effectively screen for the level of risk and assess the needs of all parties, including children, in families experiencing DV. This report provides a list of nine possible indicators for risk of child murdersuicide (e.g., the perpetrator having a history of violence; the perpetrator having obsessive and controlling personality traits which made the partner hard to live with prior to the separation and which deteriorate markedly after separation; and/or the perpetrator had a proprietary attitude toward their children or partner). This report represents one of the first assessment guides that include particular factors of risk for lethality of children exposed to DV. However, this report serves only as a guide for practitioners and is not based on empirical research.

There is no reported literature on the effectiveness of current risk assessment tools being utilized with victims of DV on identifying a child's risk for lethality, aside from a preliminary report in a thesis (36). The thesis study was a retrospective analysis that compared domestic homicide cases with child victims to domestic homicide cases where children were present but not killed. Each case was assessed using three standardized risk assessment tools: 1) the Danger Assessment (DA) (37); 2) the Ontario Domestic
Assault Risk Assessment (ODARA) (38); and 3) the Brief-Spousal Assault Form for the Evaluation of Risk (B-SAFER) (39). The findings indicated no significant differences in the overall assessment results, using the three standardized risk assessment tools, for domestic homicides with a child victim and domestic homicides with children present in the home but not killed. Furthermore, all the risk assessment tools deemed all the cases 'high-risk' with no difference between the two types of domestic homicide cases. The results from this study suggest that although risk assessment tools do not specifically assess a child's risk for lethality, children within a family experiencing DV should always be considered when assessing risk for lethality with a victim, especially among families assessed to be high risk.

\section{Implications}

Research has consistently documented the potential harm arising from the impact of exposure to DV on children $(7,6,4)$. In extreme cases of DV, children may become "collateral" victims by either being exposed to a domestic homicide or becoming victims themselves $(22,24)$. It is important for professionals working with at-risk families to be aware of the risk for lethality with children exposed to DV. Specifically, professionals should receive enhanced training on the dynamics of DV and the risk for lethality and professional associations should develop protocols for routine screening and intervention that not only considers the risk and safety of the victim but also her children. Over the past 15 years, health care professionals have increasingly recognized the impact of DV on families and several professional associations (e.g., the American Medical Association; the American College of Obstetricians and Gynecologists; the American Academy of Family Physicians) have made recommenda- 
tions around the need for universal screening $(40,41)$. However, screening rates in several health care settings remain low due to specific attitudes and beliefs among service providers (e.g., screening could be harmful; patients could be offended; it is not the responsibility of the service provider; it is not a problem within the specific health care setting) and the lack of comfort and confidence in intervening with individuals experiencing DV (41).

There is much debate over the effectiveness of universal screening and fear of unintended consequences $(40,41)$. Yet, research has indicated that screening increases disclosures of violence among patients and that most women and victims of DV endorse screening when it is conducted in a nonjudgmental and supportive environment that provides informed consent and ensures privacy (41). Physicians in states that have legislation that requires mandatory reporting of DV may be afraid of liability issues and/ or are concerned that patients who disclose violence may be forced into the legal process where they may be revictimized (40); however arresting and charging the abuser may be the only way to ensure the safety of the victim and her children. Many of the issues around universal screening can be addressed with enhanced professional training. Research has indicated that training and education can increase a professional's comfort with providing interventions and referrals and therefore can increase the frequency of screening patients (41). Furthermore, training and education on how to talk to victims of DV and explain any limits to confidentiality can ensure that professionals, who are mandated to report violence, avoid liability issues and prepare their patients for the legal process that may follow (40).

More research needs to be conducted to identify risk factors for lethality with children exposed to DV. Currently, there are no risk assessment tools that specifically screen for a child's risk to domestic homicide. Research has indicated that current risk assessment tools being used with victims of DV could not differentiate between domestic homicide cases involving child victims and domestic homicide cases where children were present but not killed (36). However, these assessment tools were able to establish that all of the domestic homicide cases were considered to be "high-risk". These results indicate that standardized risk assessment tools are effective in assessing risk for lethality but not identifying particular risk to children. Therefore, professional associations may want to consider implementing the use of a standardized risk assessment tool in their DV screening protocols and policies and ensure that children are always considered in the assessment of risk. National organizations have provided guidelines for how health care professionals can assess for domestic violence with a child or adolescent patient (42). These guidelines emphasize the importance of asking direct questions, informing about limits of confidentiality, using direct and easy to understand language, ensuring the assessment takes place without the parent in the room for adolescents or the intimate partner for a parent being assessed, conducting the assessment in the patient's first language, and ensuring a face-to-face assessment.

Once a victim discloses violence, an effective safety plan and risk management strategy needs to be put in place. Importantly, children should be considered and included in the safety planning and risk management. Professional associations need to develop protocols for effectively intervening, specifically with the victim and her children, and managing offender risk (17). Research has indicated that professionals are more likely to conduct routine screening when they have institutional support and supervision, such as standardized protocols for interventions (41). Victims should be referred to commu- 
nity services that will help provide ongoing support for herself and her children. Referrals also need to be made to assist the perpetrator to change his behavior as a spouse and parent through specific DV programs and to receive support for potentially related mental health and addictions issues (43, 44). In dealing with disclosures, it is important for the professional to provide the patient with support by expressing concern for their safety, listening without judgment, and letting the patient know that help is available. The health care professional should provide information on domestic violence and how it can impact families. Safety issues should be assessed and addressed with health care professionals encouraging parents to think about safety issues for their children. Finally, health care professionals should refer the patient to culturally appropriate supports (42).

This review is intended to be an important reminder of the risks posed to children in the context of DV. Many professionals have unique opportunities to save lives through keen observations and interventions in

\section{References}

1. Tjaden P, Thoennes N. Extent, nature, and consequences of intimate partner violence: Findings from the National Violence Against Women Survey. Washington: National Institute of Justice; 2000 July. 57 p. Report No.: NCJ181867. Available from: https://www.ncjrs.gov/pdffiles1/nij/181867.pdf

2. Sinha M. Family violence in Canada: A statistical profile, 2010. Ottawa: Statistics Canada; 2012 May. 107 p. Catalogue No.: 85-002-X. Available from: http://www.statcan.gc.ca/pub/85002-x/2012001/article/11643-eng.pdf

3. Avdibegović E, Sinanović O. Consequences of domestic violence on women's mental health in Bosnia and Herzegovina. Croat Med J. 2006:47;730-41.

4. Jaffe P, Wolfe DA, Campbell M. Growing up with domestic violence. Cambridge: Hogrefe; 2012. the face of the warning signs described above. In spite of the increased understanding that exposure to DV creates significant emotional harm to children, many professionals may not recognize the potential lethal harm to children in extreme cases of DV. Although children's deaths in the context of DV represent relatively low incidence, reviews of these tragedies suggest a pattern of missed opportunities to respond to obvious warning signs that reinforce the need for vigilance.

\section{Conclusion}

Coroner reports, inquests and domestic violence death review committees have highlighted the fact that children may be at significant risk of lethal violence in homes with domestic violence. Health care professionals need to recognize that risks to adult partners in these circumstances also pose direct risks to children. Current research and practice does not provide a basis for differentiated risk so it is appropriate to assume children are at risk if their primary care-giver is also at risk of lethal domestic violence.

5. Catalano S. Intimate Partner Violence in the United States. Washington: U.S. Department of Justice; 2007 Dec. 46 p. Available from: http://bjs.ojp. usdoj.gov/content/pub/pdf/ipvus.pdf

6. Holt S, Buckley H, Whelan S. The impact of exposure to domestic violence on children and young people: A review of the literature. Child Abuse Negl. 2008:32(8);797-810.

7. Hayes J, Trocmé N, Jenney A. Children's exposure to domestic violence. In: Alaggia R, Vine C, editors. Cruel but not unusual: Violence in Canadian families. Waterloo, ON: Wilfrid Laurier University Press; 2006. p. 201-36.

8. Cunningham A, Baker L. What about me? Seeking to understand a child's view of violence in the family. London: Centre for Children \& Families in the Justice System; 2004. 138 p. Available from: http://www.lfcc.on.ca 
9. Reitzel-Jaffe D, Wolfe, DA. Predictors of relationship abuse among young men. J Interpers Violence. 2001:16(2);99-115.

10. Wolfe DA, Wekerle C, Scott K, Straatman A-L, Grasley C. Predicting abuse in adolescent dating relationships over 1 year: The role of child maltreatment and trauma. J Abnorm Psychol. 2004:113(3);406-15.

11. Nixon KL, Tutty LM, Weaver-Dunlop G, Walsh CA. Do good intentions beget good policy? A review of child protection policies to address intimate partner violence. Child Youth Serv Rev. 2007:29(12);1469-86.

12. Friend C, Shlonsky A, Lambert L. From evolving discourses to new practice approaches in domestic violence and child protective services. Child Youth Serv Rev. 2008:30(6);689-98.

13. LaLiberte T, Bills J, Shin N, Edleson JL. Child welfare professionals' response to domestic violence exposure among children. Child Youth Serv Rev. 2010:32(12);1640-47.

14. Feingold M. Everything's not O.K. at home. Clin Pediatr. 2000:39(1);41-2.

15. Guček NK, Švab I, Selič P. The prevalence of domestic violence in primary care patients in Slovenia in a five-year period (2005-2009). Croat Med J. 2011;52:728-34.

16. American Academy of Pediatrics - Committee on Child Abuse and Neglect. The role of the pediatrician in recognizing and intervening on behalf of abused women. Pediatrics. 1998;101(6):1091-92.

17. Jaffe PG, Campbell M, Hamilton LHA, Juodis M. Children in danger of domestic homicide. Child Abuse Negl. 2012:36(1);71-4.

18. Catalano S, Smith E, Snyder H, Rand M. Female victims of violence. Washington: U.S. Department of Justice; 2009 Sept. 8 p. Available from: http://bjs. ojp.usdoj.gov/content/pub/pdf/fvv.pdf

19. Ontario Domestic Violence Death Review Committee (Ontario DVDRC). 2011 Annual Report: Domestic Violence Death Review Committee. Toronto: Office of the Chief Coroner; 2012.

20. Campbell JC, Webster D, Koziol-McLain J, Block C, Campbell D, Curry MA, et al. Risk factors for femicide in abusive relationships: results from a multisite case control study. Am J Public Health. 2003;93(7):1089-97.
21. Daly M, Wilson M. Violence against stepchildren. Curr Dir Psychol Sci. 1996:5(3);77-81.

22. Dobash RP, Dobash RE. Who died? The murder of collaterals related to intimate partner conflict. Violence Against Women. 2012:18(6);662-71.

23. Lewandowski LA, McFarlane J, Campbell JC, Gary F, Barenski C. "He killed my mommy!" Murder or attempted murder of a child's mother. J Fam Violence. 2004:19(4);211-20.

24. Jaffe PG, Juodis M. Children as victims and witnesses of domestic homicide: Lessons learned from domestic violence death review committees. Juv Fam Court J. 2006:57(3);13-28.

25. Hardesty JL, Campbell JC, McFarlane JM, Lewandowski LA. How children and their caregivers adjust after intimate partner femicide. J Fam Issues. 2008:29(1);100-24.

26. Eth S, Pynoos R. Children who witness the homicide of a parent. Psychiatry. 1994:57(4);287-306.

27. Kaplan T, Black D, Hyman P, Knox J. Outcome of children seen after one parent killed the other. Clin Child Psychol Psychiatry. 2001:6(1);9-22.

28. Black D, Kaplan T. Father kills mother: Issues and problems encountered by a child psychiatric team. Br J Psychiatry. 1988;153(5):624-30.

29. Fernandez-Lanier A, Gilmer JA. Criminal justice research report: Domestic homicide in New York State, 2007. Albany: Division of Criminal Justice Services Office of Justice Research and Performance; 2008. p. 10.

30. Marleau JD, Poulin B, Webanck T, Roy R, Laporte L. Paternal filicide: a study of 10 men. Can J Psychiatry. 1999:44(1);57-63.

31. Websdale N. Understanding domestic homicide. Boston: Northeastern University Press; 1999.

32. Hamilton LHA, Jaffe PG, Campbell M. Assessing children's risk for homicide in the context of domestic violence. J Fam Violence. 2012;1-11.

33. Kropp PR. Intimate partner violence risk assessment and management. Violence Vict. 2008:23(2);202-20.

34. Shlonsky A, Friend C. Child maltreatment and domestic violence editorial: Current state of knowledge and emerging strategies for policy and practice. Brief Treat Crisis Interv. 2007:7(4);24952. 
35. Australia. Attorney General's Department. Screening and assessment in the familyrelationship centres and the family relationship advice line: Practice framework and guidelines. Canberra: Australian Catholic University; 2006. p. 89.

36. Olszowy L. (2011). Effectiveness of risk assessment tools in differentiating child homicides from other domestic homicide cases [Honours Thesis]. [London $(\mathrm{ON})$ ]: Western University: 2011. p. 55.

37. Campbell JC. Nursing assessment of risk of homicide for battered women. ANS Adv Nurs Sci. 1986;8(4):36-51.

38. Hilton NH, Harris GT, Rice ME, Lang C, Cormier CA, Lines, KJ. A brief actuarial assessment for the prediction of wife assault recidivism: The Ontario domestic assault risk assessment. Psychol Assess. 2004:16(3);267-75.

39. Kropp PR, Hart SD, Belfrage H. Brief spousal assault form for the evaluation of risk user manual. Vancouver: ProActive Solutions; 2005.
40. Devi S. US guidelines for domestic violence screening spark debate. Lancet. 2012:379(9815);506.

41. Todahl J, Walters E. Universal screening for intimate partner violence: a systematic review. J Martial Fam Ther. 2011:37(3);355-69.

42. Mcalister Groves B, Augustyn M, Lee D, Sawires P. Identifying and Responding to Domestic Violence. Consensus Recommendations for Child and Adolescent Health. San Francisco: Family Violence Prevention Fund; 2002.

43. Gondolf E. Batterer Intervention Systems. Thousand Oaks: Sage; 2001.

44. Scott KL, Crooks CV. Preliminary evaluation of an intervention program for maltreating fathers. Brief Treat Crisis Interv. 2007:7(3);224-38.

Citation: Jaffe PG, Campbell M, Olszowy LP. Health care professionals' role in preventing child homicides in the context of domestic violence. Paediatrics Today. 2013;9(1):55-63. 